\title{
The Research on Strategies of China's Green Finance Development
}

\author{
Ying Shi \\ Management Department, Changchun Institute of \\ Technology \\ Northeast Asian Studies Academy, Jilin University \\ Changchun, China \\ CGA, Certified General Accountants Association of \\ Canada \\ yingshicn@hotmail.com
}

\author{
Geng Xiaozhong \\ School of Electrical and Information Technology, \\ Changchun Institute of Technology \\ Department of Computer Science and Technology, Jilin \\ University \\ Changchun, China \\ gengxiaozhongcn@sina.com
}

\begin{abstract}
Green finance (ecological finance) is an important tendency to develop modern financial industry. The development of green finance has significant role to protect the ecological environment, accelerate economy and develop the financial industry. Green Finance is also the necessary way to balance the relationship among economy, society and environment, and to satisfy the needs for sustainable development. Currently, with the rapid development of economy, the whole financial concentration level is improved. However, many problems should be designed to take into account. How to develop Chinese financial industry becomes an important issue that needs to be re-considered in post-crisis era. To that end, it is an exploring field to do deep investment in the economic development model of green finance in order to achieve the future development of China's financial industry, finally promote financial sustainable development and Social Harmonious Development.
\end{abstract}

Keywords-Green finance; Chinese Financial industry; Sustainable development; Development Strategies

\section{INTRODUCTION}

Green finance is a new concept, which is also called environmental finance or sustainable financing, first appeared in 1997.Green finance theory began from American "Super Fund Case” in 1980's. It was required to be responsible to the environment pollution. After that, The British, Japan and European Union governments and international organizations had done many researches and accumulated a lot of experiences. The main concern of the green financial development is market driven model. Such as the United States and European Union, they established perfect system related to legislations, systems, exchange markets, market participants and intermediary. There is no standard definition from domestic academics until now. The representative view is: Green finance is also called environment finance or sustainable financing and will protect the ecological environment by using financial tools (The traditional American dictionary, fourth edition, 2000); It mainly supports the green industry through financial policies.(Xiuxing $\mathrm{He}$, 1998 ) ; The financial department regards the environment protection as a basic state policy and will promote financial sustainable development by realizing environmental and economic development (Jianliang Gao, 1998); also they add the green finance theory to the trade policies when make decisions in economic and capital markets. (Pan Yue, 2007). In summary, Green finance means that the financial department regards the environment protection as a basic policy and considers the potential environment effect when make investment decision. In addition, it considers all the potential return, risk and cost related to environment in normal business life. In the routine business, the financial institutions use the green finance theory as new development way in order to change the new driving forces of economic development and strengthen the protection of the ecological environment or environmental pollution management through guidance the use of economic and social resources and promote the sustainable development of society. Moreover, green finance has two meanings: one is how to let the financial industry to promote environmental protection and sustainable development of economic society, and another is refers to the sustainable development of the financial industry itself.

Green finance is the new direction of financial industry development in low carbon economy. It puts more emphasis on human social environment and treats the environment protection and the effective utilization of resources as its standard activity result measurement by leading each economic body to pay great attention to natural ecological balance. It requires the financial activities, environmental protection and the ecological balance to be developed at the same time in order to finally achieve the sustainable development of society and economy. Since the reform and opened up, along with China's rapid economic development and increasing environment problems, facing the energy conservation and emission reduction, environment protection, circular economy and sustainable development and other difficult problems, especially after the financial crisis, Chinese government and economical experts' particular concerned the change to establish the green finance. The development of green finance could guarantee the sustainable development of economic society. Reducing cost of information becomes one of the conditions. This requires the financial growth mode to be setup in order to save resources, reduce cost, increase 
benefits and improve the environment. The fact is that the conflict between social economic development and the limitation of resource environment has been increasingly serious. Accordingly, carrying out green finance development increasingly shows its importance and, at the same time, the green finance can promote the development of China's financial industry.

\section{GREEN FINANCE AND ECONOMIC SUSTAINABLE DEVELOPMENT}

The investors could make investment and gain profits based on the change of environment and climate under the marketable economy by regarding the finance as the central part of modern economic development and regarding the capital as the main body of the market resources allocation. The state council development research center (2009) did the study by using property rights and externality theory and they concluded that it is possible that energy saving and emission reduction will become a profitable behavior and low carbon economy development mode will replace traditional development mode if all countries make a clear definition of emissions and strict protection regulation.

The financial industry must guarantee to meet the requirements of investment in environmental protection industry in order to maintain sustainable development and ensure the long-term profit. Thus, in the process of transition to low carbon economy, China needs to transform large quantities of traditional industry and promotes the growth for new industry by raising the level of environmental protection standard. This would provide a broad space for developing green finance. In the procedure of development, the direct target of green finance is the main body of microcosmic economy. The way to develop the green finance is to guide and adjust capital distribution of the financial ecological system and maintain the inner and outsider financial ecosystem environment in good condition to promote the interactive development. The economy can be developed sustainably only based on resource saving and financial ecological system set up. Financial industry could provide the products and services for efficient energy finance, environment finance and carbon finance to achieve environmental protection, realize financial industry sustainable development through sustainable business models, provide favorable conditions for financial industry agglomeration by combining social responsibility and sustainable theory together.

Green finance promotes sustainable development of economy through the impacts of technology innovation, enterprise behavior, public investment, business orientation and avoids market failure on energy conservation and emission reduction in a direct and indirect role. Furthermore, different types of financial institutions also differently affected the sustainable development through direct or indirect; Positive or negative and Long-term or short-term paths. Stated briefly, first, green finance has positive affection to the cash flow between different industries. Financial institutions invest by green way and adjust the input and output portfolio in order to change the industry to that has high level utilization rate and environmental protection. Also, there is benefit for the enterprise decision-making. Financial institutions invest through green way and get the decision-making support by considering the risk of environment. This will change the environment and promote the sustainable development of economy indirectly. Finally, there is benefit for the industry development. Financial institutions could provide investment and financial services to environment protection industry which has resources utilization, new invention and environmental pollution issues. This will improve the ecological environment and promote sustainable development of economy. At the same time, the sustainable development of economy will provide a good external environment for financial industry and will promote healthy development of financial industry. Then form interactive win-win situation and finally promote the development of the financial industry agglomeration. From the view of practice of green finance, foreign banking developed the green financial practice earlier; China started late and had less experience but has fast development in recent years.

\section{THE ANALYSIS OF GREEN FINANCIAL INDUSTRY DEVELOPMENT IN CHINA}

At the beginning of $1980 \mathrm{~s}$, along with the global economy integration and the rapid development of the financial industry, international financial resources accelerate the floating in regions. Along with the environmental protection and economic sustainable development system become increasingly perfect, green finance theory gradually is accepted by the international main bank. Currently, many Chinese commercial banks have gradually realized that the effective way to realize the scientific management model is to develop green finance. These banks did a lot of research on the development of green finance and have gained certain achievements. However, since China's green finance development is still in the initial stage, the banks face many problems in the process of development, mainly reflected in the following respects:

First, the development of China's green finance lack of suitable policies and suitable market environment. In the process of the socialist market economy development, China's environmental protection policies and regulations are not perfect and the environmental economic policy is still in the stage of exploration. In addition, the ability to implement local environment protection policies is not strong. That cause the implementation of environment protection policies is in difficult situation. At the same time, most financial institutions lack of related environment protection knowledge, have high cost to gain information and haven't enough related policies and regulations to protect the environment. As a result, the green financial industry can not be properly promoted. Second, the development of China's green finance lacks of encouragement and supervision. Most shareholders, managers and employee who work in China's financial institutions do not realized that they have the social responsibilities. They did not setup proper systems to match the development of green finance inside the financial institutions. Also, the incentive mechanism constraint system is not setup to develop green finance. Economic interests are paid more attention. The supervision to the financial institutions hasn't been done by 
society, companies and individuals. Third, the plan and preparation work are slow. Green finance becomes a tendency for the international financial institutions. However, China's financial institutions do not put the green finance to strategies level and often delay the plan and preparation work for green finance. Some financial institution have carried on the initial practice stage which is just at the business level, and have no long-term plans and goals. Finally, the development of intermediary service system for China's green finance lags behind. The financial institutions are not familiar with the trade value, operation mode, project development and trade regulations. The professional service agents are not enough and the principals for the trade market are not obvious.

In conclusion, the main reasons are as followed: one is that the lack of government behaviors. From the experiences of foreign green financial industry development, the most important and effective supports to develop the green finance are the adjustments of government behaviors and the agreements between banks and the government. The second reason is that most enterprises have inappropriate activities. It's difficult for many enterprises to invest a lot of money to conserve energy and reduce emission under the government constraint. Also, the enterprises will reduce the ability to pay debts because of the environment pollution problems. Therefore, the enterprises' environment behavior stops the sustainable development of financial institutions. The last one is that the financial industry itself has problem. Such as, the financial industry does not understand the concept of sustainable development in proper way and lack of responsibilities for all the society.

\section{THE DEVELOPMENT STRATEGIES OF CHINA's GREEN FINANCE}

Under the global development of green finance, in order to develop financial industry, the Chinese government should setup a series of policies to support the development of financial industry, taking advantage of the financial institutions, step by step to promote the development of China's green financial industry.

First, setup the green financial system and built the market for green finance. China should built perfect financial basic law by combining the characteristics between Chinese culture and financial industry and learning from foreign advanced green finance development system. Also, the detail regulations of green finance should be implemented in operation area and be confirmed by law. At the same time, the supervision system of green finance should be established and gradually improved. The exchange market of credit tools based on carbon emissions should be established in the project market, voluntary emissions markets and quota market. Therefore, the local independent green financial trading mechanism to be suitable to China's national conditions would be established on a higher level.

Secondly, make green finance instruments and setup the construction of green finance. According to the layout of financial market development, based on the principle from the base to the innovation, from simple to complex, gradually create original green finance instruments, green finance derivatives and provide more market risk management and arbitrage tools. Furthermore, develop financial institution and create excellent conditions for financial agglomeration.

Finally, Rich green financial culture, improve the financial supervision. Green finance culture is very important aspect to realize the sustainable development of financial industry. Based on the green finance theory, a series of green planning advertisements and green marketing behaviors should be made. Thereby, Green finance could be developed harmoniously and better business environment could be created through building green spirit culture, green behavior culture and green image culture. In addition, learning form foreign countries' supervision system experience, according to green financial characteristic of risk and special operation mode, China could setup supervision system laws, adjust supervision way, innovate supervision idea and perfectly built green financial regulatory framework in order to guarantee the development of green finance.

\section{REFERENCES}

[1] Keqiang Li, some questions about how to adjust economic construction to promote sustainable development[DB/OL]. The central government website, www.gov.cn, 2010-6-1.

[2] Kunmin Zhang, Jiahua Pan, Dapeng Cui. Low Carbon Theory [M].Beijing : China's Environmental Science Press, 2009.

[3] Peter M. Senge. The Necessary Revolution : The Creation and Practice of Sustainable Society[M].Beijing : Citic Publishing House, 2009.

[4] Gang Fan, the development to low carbon: China and the world---the advices from Chinese economists[M]. the press of China economy,2010.

[5] Wei An. The concept, mechanism and practice of green finance[J]. economic survey, 2008,(5) : 156 158.

Kewei Zha.Green finance and the financial sustainable development[J].Financial Aspect,2010, ( 5):15 18. 